ScIDoC

International Journal of Dentistry and Oral Science (IJDOS)

ISSN: $2377-8075$

\title{
Fracture Resistance of Mesio-Occlusal-Distal Cavities Restored with Composite, Resin Modified Glass Ionomer Cement and Zirconomer - An In Vitro Study
}

Research Article

\section{Swathi UB ${ }^{1}$, Sindhu Ramesh ${ }^{2 *}$, S.Pradeep ${ }^{3}$}

${ }^{1}$ Department of Conservative Dentistry and Endodontics, Saveetha Dental College and Hospitals, Saveetha Institute of Medical and Technical Sciences, Saveetha University, Chennai, India.

${ }^{2}$ Professor, Department of Conservative Dentistry and Endodontics, Saveetha Dental College and Hospitals, Saveetha Institute of Medical and Technical Sciences, Saveetha University, Chennai, India.

${ }^{3}$ Reader, Department of Conservative Dentistry and Endodontics, Saveetha Dental College and Hospitals, Saveetha Institute of Medical and Technical Sciences, Saveetha University, Chennai, India.

\section{Abstract}

Introduction: Zirconomer is a recently introduced cement that combines the benefits of amalgam and conventional glass ionomer and offers the strength and durability of amalgam with the protective benefits of glass ionomer and also eliminates the hazard of mercury.

Aim: To compare the fracture resistance of maxillary premolars with MOD cavities when restored with Zirconomer, Resin modified glass ionomer cement and Composite.

Materials and Methodology: Forty extracted non-carious intact human maxillary premolars were collected and stored in distilled water and divided into two Control groups with five teeth each $(n=5)$ and three experimental groups with 10 teeth each $(n=10)$ Group I: Positive control with no cavities prepared, Group II: Class II MOD cavities were prepared but the cavities were not restored (Negative control), Group III: Cavities were restored with composite (Charisma;Heraeus Kulzer,Germany), Group IV: Cavities were restored with Resin modified Glass Ionomer Cement (Fuji II LC,GC corporation, Tokyo, Japan), Group V: Cavities were restored with Zirconomer (Shofu Inc, Japan). Fracture resistance was tested with a cross head speed of about $1 \mathrm{~mm} /$ min when the specimen was loaded in a Universal Testing Machine. The mean fracture resistance of the groups were statistically analyzed using One way ANOVA and post hoc test $(\alpha=0.05)$.

Results: There was no significant difference between Group 1 (positive control) and Group 5 (zirconomer), (P>0.05). Group 5 (Zirconomer) and Group 3 (Composite) showed better fracture resistance in comparison to Group 2 (Negative control), and Group 4 (Resin modified GIC) $(\mathrm{p}<0.05)$.

Conclusion: Zirconomer can be advocated as a potential posterior restorative material of choice.

Keywords: Composite Resin; Fracture Resistance; Glass Ionomer Cement; Resin Modified GIC; Zirconomer.

\section{Introduction}

Removal of tooth structure by cavity preparation can cause weakening of the tooth structure and increase in their susceptibility to fracture $[1,2]$. Weakening of teeth by means of preparation of mesio-occlusal-distal (MOD) cavities and the effect of restorations in strengthening the remaining tooth structure and tissues was performed in several studies. Depending on the extent of the cavity, restorative treatment also contributes to be an important factor for an incomplete or complete tooth fracture [3, 4]. A study that was conducted by Joynt et al., 1987 have proved that preparation of an occlusal cavity tends to reduce the tooth stiffness by about $20 \%$ [5]. If a marginal ridge is involved and removed during this cavity preparation the occlusal cavity tends to transform into a proximal cavity and the tooth stiffness further reduces by 2.5 folds resulting in an overall reduction in tooth stiffness by $46 \%$. If both marginal ridges are included in the cavity preparation design, the stiffness in the tooth structure tends to decrease overall by about $63 \%[5,6]$. In posterior teeth like the maxillary premolars, the anatomy of the teeth is such that it tends to frac-

\section{*Corresponding Author:}

Sindhu Ramesh,

Professor, Department of Conservative Dentistry and Endodontics, Saveetha Dental College and Hospitals, Saveetha Institute of Medical and Technical Sciences, Saveetha University, 162, PH Road, Chennai 600077, TamilNadu, India.

Tel: 9840136543

E-mail: sindhuramesh@saveetha.com

Received: November 05, 2020

Accepted: November 18, 2020

Published: November 25, 2020

Citation: Swathi UB, Sindhu Ramesh, S.Pradeep. Fracture Resistance of Mesio-Occlusal-Distal Cavities Restored with Composite, Resin Modified Glass Ionomer Cement and Zirconomer - An In Vitro Study. Int J Dentistry Oral Sci. 2020;S10:02:008:44-49. doi: http://dx.doi.org/10.19070/2377-8075-SI02-010008

Copyright: Sindhu Ramesh 2020 . This is an open-access article distributed under the terms of the Creative Commons Attribution License, which permits unrestricted use, distribution and reproduction in any medium, provided the original author and source are credited. 
ture the cusps under occlusal load [7, 8]. Preparation designs done for posterior composite restoration differ from the preparations done for amalgam restorations in the depth of the cavity and occlusal form the depth should be more swallower and the occlusal form should be narrower and the proximal extensions (facial and lingual) should be placed in areas that are more accessible and can be seen, probed and polished. Rounding of the internal line angles and placement of retentive grooves in proximal line angles (axio-facial and axio-lingual) and also in the gingival wall. Beveling is recommended for proximal margins but the occlusal margins should not be beveled. Amalgam was used traditionally as best build up material over years $[9,10]$. However, due to certain disadvantages of amalgam like slow setting process, mercury content, unpleasant colour that was not esthetic alternative core buildup materials were introduced over time [11].

Glass ionomer cement has inferior properties like tensile strength [11-14]. Resin modified GIC (RMGIC) was introduced due to these inferior properties and it is a hybrid combination of water soluble polymers or polymerizable resins to conventional GIC and they were produced in an attempt to strengthen mechanical properties of the conventional GIC and also prevent high solubility. Composite resins are improving on daily basis because of their chemical ingredients, excellent bonding ability, conservative tooth preparation, preservation of tooth structure, and esthetics. Composite resins are the materials of choice in anterior teeth due to their superior esthetics, but in the posterior region, properties such as good mechanical properties are to be taken into consideration while considering material of choice. They should also have a compressive strength that is equal to or more than tooth inorder to resist the masticatory forces [5].

When a restorative material tends to have lower compressive strength than the tooth material most often will lead to fracture or failure of the restoration $[6,7]$. Zirconomer is a recently introduced cement that combines the benefits of amalgam and conventional glass ionomer. It tends to offer the strength and durability of amalgam with the protective benefits of glass ionomer and also eliminates the hazard of mercury. Zirconomer goes through a process of controlled micronization which helps the cement to achieve optimal particle size and characteristics. Zirconomer was added with special zirconia fillers to match the strength and durability of conventional amalgam along with sustained high fluoride release,the cement is also packable and condensable like the conventional amalgam and proves to have better properties. This cement avoids disadvantages of amalgam like mercury toxicity, risk of corrosion along with thermal conductivity and expansion.

The high flexural modulus and compressive strength of Zirconomer provides more longevity of the cement in stress bearing ar- eas. It chemically bonds to enamel/dentin and has a coefficient of thermal expansion similar to that of the tooth resulting in low interfacial stresses and restorations that are long lasting. It has an adequate working time with snap-set reaction along with easy mixing and handling characteristics that tends to minimize chair side time and enables ease of bulk placement along with excellent resistance to abrasion and erosion [15]. Many factors favour caries progression and should be considered while treating and restoring caries lesions [16-27].

This study aimed to compare the fracture resistance of maxillary premolars with MOD cavities when restored with Zirconia reinforced Glass ionomer cement (Zirconomer) and other conventional posterior restorative materials like RMGIC and Composite.

\section{Materials and Methods}

40 extracted human maxillary premolars that were for orthodontic purposes, were selected.The teeth were then randomly divided into 2 Control groups with five teeth each $(n=5)$ and three experimental groups with 10 teeth each $(n=10)$. Any calculus deposits and soft tissue were removed from the selected teeth by means of a hand scaler. The teeth were cleaned with pumice and examined under $\times 10$ magnification for detection of any pre-existing defects prior to the start of the study. Post-extraction storage in $10 \%$ neutral buffered formalin was done for four days, and the teeth were stored in tap water at room temperature until it was used.Each tooth was fixed, with its crown uppermost and long axis vertical in rings of polyvinyl chloride (PVC) with specific dimensions such as length of $25 \mathrm{~mm}$, diameter of $10 \mathrm{~mm}$, in auto-cured acrylic resin. The level of the resin limited was at $1.0 \mathrm{~mm}$ below the cemento -enamel junction. Class II MOD cavities were prepared in all teeth except the positive controls within specific dimensions of $2 \pm 0.2 \mathrm{~mm}$ pulpal width, $2 \pm 0.2 \mathrm{~mm}$ gingival width, $3 \pm 0.2$ $\mathrm{mm}$ buccolingual width (Figure 1). These dimensions were verified using a periodontal probe. The facial and lingual walls were prepared in such a way that they were parallel to each other while the cavosurface angle was at 90 degrees (Figure 1).

\section{Groups}

Group I: Positive control with no cavities prepared.

Group II: Negative control, MOD cavity preparations have been done but were left unrestored.

Group III: Class II MOD cavities were prepared; matrix band \& retainer were adapted and was restored with composite. (Charisma;Heraeus Kulzer,Germany)

Group IV: Class II Mod cavities were prepared and restored with RMGIC. The cavities were well adapted with a matrix band and retainer prior to restoration. (Fuji II LC, GC corporation, Tokyo,

Figure 1. Figure representing Diagrammatic representation of the standardized Cavity Preparation.

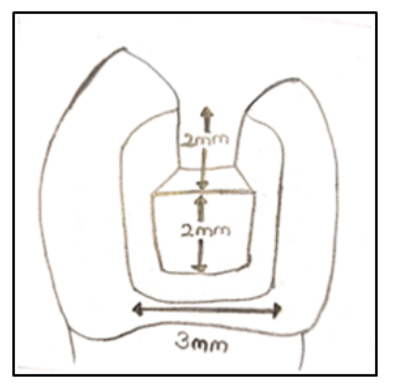


Japan).

Group V: Class II MOD cavities were prepared and a matrix band $\&$ retainer were tightly adapted to the tooth and then the teeth were restored with Zirconomer (Shofu Inc, Japan).

The specimens were stored in distilled water followed by a thermocycler at cycles of 5,000 at temperatures of $5^{\circ} \mathrm{C}$ and $55^{\circ} \mathrm{C}$. Each cycle was placed for a time of about 15 seconds in each temperature.

The specimens were tested individually using a universal testing machine (Instron-Used from saveetha dental college white lab) (Figure 2) and each specimen was subjected to compressive loading with the help of a rectangular gauge, crosshead speed of $1 \mathrm{~mm} / \mathrm{min}$ until the cusp was fractured (Figure 3).

The gauge should come in contact with the inclined planes of the facial and palatal cups in the buccolingual direction and beyond the margins of the restorations (Figure 2 and 3). Peak load to fracture was calculated and it was calculated in terms of newton for the 40 specimens tested. The statistical analysis was performed for mean, standard deviation, One-Way ANOVA and Post hoc Bonferroni test.

\section{Results and Discussion}

Mean values required for the tooth to fracture following compression and standard deviations were calculated for each experimental group. The results showed no significant difference between Group 1 (positive control) and Group 5 (zirconomer), ( $\mathrm{P}>0.05)$. Group 5 (Zirconomer) and Group 3 (Composite) showed better fracture resistance in comparison to Group 2 (Negative control), and Group 4 (Resin modified GIC). On comparison of Group 3 (Composite) and Group 5 (Zirconomer) there was no significant difference $(\mathrm{p}>0.05)$, however zirconomer had higher fracture resistance (Table 1) (Figure 4).

A fracture is a complete or incomplete break which results when excessive force is applied. In the oral cavity these excessive forces can occur due to mastication. In this study a load is applied to the tooth such that the tooth tends to fracture under compression. Fracture resistance is an important property directly related to cracking of the tooth $[3,28]$. These cracks can be internal or external cracks. Masticatory forces on restored or unrestored teeth have a tendency to deflect the cusps when the tooth are under stress [29]. Even though in vitro studies are not an actual repro-

Figure 2. Figure representing Specimen Loaded in Instron.

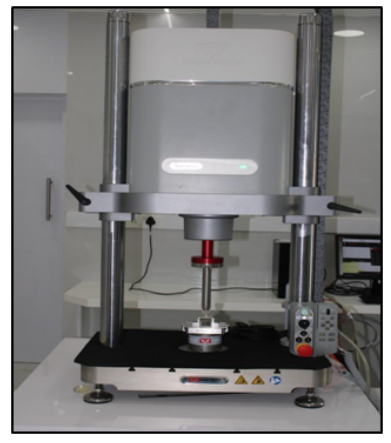

Figure 3. Figure representing Specimen Loaded in Instron.

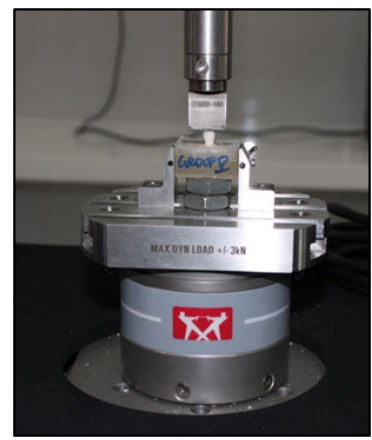

Table 1. Table showing Mean and S.D of Groups Tested for Fracture Resistance. Zirconomer had more Fracture Resistance in Comparison to other Test Groups.

\begin{tabular}{|c|c|c|c|}
\hline \multicolumn{4}{|c|}{ Max Force (N) } \\
\hline Groups & Mean & $\mathbf{N}$ & Std. Deviation \\
\hline Positive Control & 1632.4720 & 5 & 489.88636 \\
\hline Negative Control & 421.8540 & 5 & 161.93262 \\
\hline Composite & 1333.6640 & 10 & 84.54830 \\
\hline RMGIC & 913.4390 & 10 & 113.05491 \\
\hline Zirconomer & 1431.9510 & 10 & 280.01236 \\
\hline Total & 1176.5543 & 40 & 436.43214 \\
\hline
\end{tabular}


Figure 4. Figure showing the mean and SD of all the groups.Similar alphabets denotes no significant difference $(p>0.05) . *$ denotes a significant difference when compared to the other two groups ,positive control group and Zirconomer has better fracture resistance $(\mathrm{p}<0.05)$.

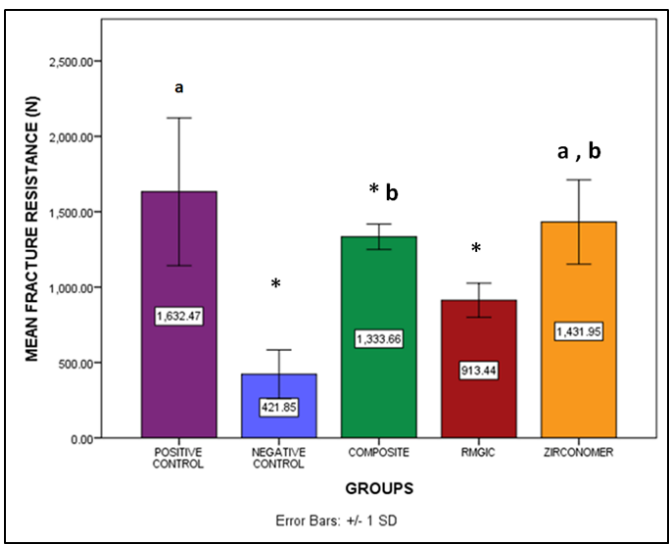

duction of a typical chewing stroke, they tend to apply a continuously increasing force until the tooth fractures, they represent an important source of information on the structural integrity of the tooth. Ideally, any material that is used to restore missing tooth structure should reinforce the tooth structure lost and minimize risk of cuspal fracture. In this study, sound unprepared teeth in comparison to teeth restored showed significantly higher resistance to catastrophic fracture. Deleterious effects that cavity preparation has on the fracture resistance of posterior teeth have been shown by previous studies [30].

According to Hood, 1991 who analysed the biomechanics of the intact, prepared and restored tooth considered that the degree of cuspal deflection increases with increase in the depth of the preparation [31]. According to Mondelli, 2005 teeth with large MOD cavities are weakened severely as there is loss of substantial tooth structure these teeth tend to become more susceptible to fractures [32]. In the present study, carried out teeth restored with zirconomer showed the highest fracture resistance to fracture due to presence of Yttrium stabilized zirconia (YSZ) particles that are present in zirconomer which provide high strength and elastic modulus [33]. Powder Components of the zirconomer namely the polyalkenoic acid and the glass components have been modified in order to improve properties of the strength and impart high strength to it .Composition of the zirconomer cement include zirconium oxide, glass powder, $1-10 \%$ of tartaric acid, $20-50 \%$ of polyacrylic acid and deionized water. Zirconium oxide is the main component present in zirconomer and it originated from baddeleyite that contains zirconia in the range of $96.5 \%$ to $98.5 \%$. Zirconia particles are significantly harder than glass particles that are present in conventional GIC contributing to the reason for higher fracture resistance in zirconomer [34]. Continuous formation of aluminium salt bridges, which causes an improvement in the strength of the cement improving the mechanical properties of the cement. YSZ - GIC are micro sized powders with bimodal particle distribution and high density of glass ionomer cement which inturn contributes to their high mechanical properties [34]. The bonding capability of GICs to dentin proved the fact that the bonding of GICs to dentin is poor (weak) or somewhat nonexistent [35-37].

Resin modified GIC (RMGIC) is a hybrid combination of water soluble polymers or polymerizable resins to the conventional GIC. RMGICs were produced in an attempt to strengthen con- ventional GIC with better mechanical properties and to prevent high solubility [38]. In the posterior region, composite resins should have good mechanical properties like high compressive strength equal to that of the tooth inorder to resist the masticatory forces [39]. In this study, bulk fill composite resins were used to fill mod cavities and their fracture resistance was tested using the universal testing machine.

According to a study performed by Burke et al., Zirconomer was found to be slightly more fracture resistant than conventional amalgam [40]. Zirconomer showed best fracture resistance, this is mainly due to Yttria stabilized Zirconia particles present in the material that increases the compressive strength [33]. Properties in zirconomer that contribute to outstanding strength, durability and sustained fluoride protection proves that this cement can be used for posterior restorations in patients with high caries incidence also in cases in which strong structural cores and bases are required. Many factors favour caries progression and should be considered while treating and restoring caries lesions [41-43]. According to results of a study done by Y.W Gu. et al. Yttria stabilized zirconia (YSZ) particles can be used instead of amalgam alloy in Miracle Mix. Mechanical properties of YSZ-glass ionomer cements have been proven to be improved and advantageous in comparison with conventional glass ionomer cements [44].

\section{Conclusion}

Within the limitations of this study it can be concluded that Zirconomer can be used as the material of choice in comparison with other posterior restorative materials due to their better properties and greater resistance to fracture under stress. Zirconomer restorations have proved to be an effective alternative to resin modified glass ionomer cement and composite. Yttria stabilized Zirconia particles present in the material is responsible for increase in the fracture resistance of the material.

\section{Clinical Significance}

The high flexural modulus and compressive strength of Zirconomer provides more longevity of the cement in stress bearing areas. It chemically bonds to enamel/dentin and has a coefficient of thermal expansion similar to that of the tooth resulting in low interfacial stresses and restorations that are long lasting. It has an adequate working time with snap-set reaction along with easy 
mixing and handling characteristics that tends to minimize chair side time and enables ease of bulk placement along with excellent resistance to abrasion and erosion.

\section{Study Limitations}

This study was confined to a smaller sample size. Apart from fracture resistance other mechanical properties of ziconomer was not evaluated in the current study.

\section{Future Scope}

Further studies can be conducted with a larger sample size and evaluating the microleakage, flexural strength, shear bond strength of zirconomer in comparison with other restorative materials.

\section{Author Contributions}

Draft Preparation, Data collection, Sample Preparation was done by Swathi UB. Statistical analysis was done by. Pradeep S. Reviewing, corrections done by Sindhu Ramesh.

\section{Acknowledgement}

With Sincere gratitude, we acknowledge the staff members of the department of Conservative Dentistry and Endodontics, Saveetha Dental College and study participants for their extended support towards the completion of research.

\section{References}

[1]. Joynt RB, Davis EL, Wieczkowski Jr G, Williams DA. Fracture resistance of posterior teeth restored with glass ionomer-composite resin systems. The Journal of prosthetic dentistry. $1989 \mathrm{Jul}$ 1;62(1):28-31.

[2]. Eakle WS, Stephan Eakle W. Effect of bonded amalgam on the fracture resistance of teeth. The Journal of Prosthetic Dentistry. 1992; 68: 257-60. PMID: 1501170.

[3]. Hamouda IM, Shehata SH. Fracture resistance of posterior teeth restored with modern restorative materials. J Biomed Res. 2011; 25: 418-24. PMID: 23554719.

[4]. Azeem RA, Sureshbabu NM. Clinical performance of direct versus indirect composite restorations in posterior teeth: A systematic review. J Conserv Dent. 2018; 21: 2-9. PMID: 29628639.

[5]. Joynt RB, Wieczkowski G, Klockowski R, Davis EL. Effects of composite restorations on resistance to cuspal fracture in posterior teeth. J Prosthet Dent. 1987; 57: 431-5. PMID: 3471955.

[6]. Rezvani MB, Mohammadi BM, Mollaverdi F, Moradi Z, Soboot AR. Comparison of direct and indirect composite resin restorations effect on the fracture resistance of maxillary premolars (An in vitro study). 2012.

[7]. Mondelli RFL, Ishikiriama SK, de Oliveira Filho O, Mondelli J. Fracture resistance of weakened teeth restored with condensable resin with and without cusp coverage. J Appl Oral Sci. 2009; 17: 161-5. PMID: 19466244

[8]. Mondelli RF, Barbosa WF, Mondelli J, Franco EB, Carvalho RM. Fracture strength of weakened human premolars restored with amalgam with and without cusp coverage. Am J Dent. 1998; 11: 181-4. PMID: 10388373.

[9]. Van Nieuwenhuysen J-P, D'Hoore W, Carvalho J, Qvist V. Long-term evaluation of extensive restorations in permanent teeth. J Dent. 2003; 31: 395405. PMID: 12878022.

[10]. Wassell RW, Smart ER, St George G. Crowns and other extra-coronal restorations: cores for teeth with vital pulps. Br Dent J. 2002; 192: 499-502, 505-9. PMID: 12047122. 2/

[11]. Petronijević B, Marković D, Šarčev I, Anđelković A, Jeremić Knežević M. FRACTURE RESISTANCE OF RESTORED MAXILLARY PREMOLARS. CONTEMPORARY MATERIALS. 2013; 3: 219-25.

[12]. Staninec M. Retention of amalgam restorations: undercuts versus bonding. Quintessence Int. 1989; 20: 347-51. PMID: 2667020.

[13]. Marchan SM, Coldero L, White D, Smith WAJ, Rafeek RN. Cusp fracture resistance of maxillary premolars restored with the bonded amalgam tech- nique using various luting agents. Int J Dent. 2009; 2009: 946830. PMID: 20339450.

[14]. Medina Tirado JI, Nagy WW, Dhuru VB, Ziebert AJ. The effect of thermocycling on the fracture toughness and hardness of core buildup materials. J Prosthet Dent. 2001; 86: 474-80. PMID: 11725275.

[15]. Nandakumar M, Nasim I. Comparative evaluation of grape seed and cranberry extracts in preventing enamel erosion: An optical emission spectrometric analysis. J Conserv Dent. 2018; 21: 516-520. PMID: 30294113.

[16]. Manohar MP, Sharma S. A survey of the knowledge, attitude, and awareness about the principal choice of intracanal medicaments among the general dental practitioners and nonendodontic specialists. Indian J Dent Res. 2018; 29: 716-20. PMID: 30588997.

[17]. Jenarthanan S, Subbarao C. Comparative evaluation of the efficacy of diclofenac sodium administered using different delivery routes in the management of endodontic pain: A randomized controlled clinical trial. J Consery Dent. 2018; 21: 297-301. PMID: 29899633.

[18]. Malli Sureshbabu N, Selvarasu K, V Jayanth Kumar, Nandakumar M, Selvam D. Concentrated Growth Factors as an Ingenious Biomaterial in Regeneration of Bony Defects after Periapical Surgery: A Report of Two Cases. Case Rep Dent. 2019; 2019: 7046203. PMID: 30805222.

[19]. Siddique R, Nivedhitha MS, Jacob B. Quantitative analysis for detection of toxic elements in various irrigants, their combination (precipitate), and para-chloroaniline: An inductively coupled plasma mass spectrometry study. J Conserv Dent. 2019; 22: 344-350. PMID: 31802817.

[20]. Teja KV, Ramesh S, Priya V. Regulation of matrix metalloproteinase- 3 gene expression in inflammation: A molecular study. J Conserv Dent. 2018; 21: 592-596. PMID: 30546201.

[21]. Rajakeerthi R, Ms N. Natural Product as the Storage medium for an avulsed tooth - A Systematic Review. Cumhuriyet Dental Journal. 2019; 22: 24956.

[22]. Siddique R, Nivedhitha MS. Effectiveness of rotary and reciprocating systems on microbial reduction: A systematic review. J Conserv Dent. 2019; 22: 114-22. PMID: 31142978.

[23]. Janani K, Sandhya R. A survey on skills for cone beam computed tomography interpretation among endodontists for endodontic treatment procedure. Indian J Dent Res. 2019; 30: 834-8. PMID: 31939356.

[24]. Siddique R, Sureshbabu NM, Somasundaram J, Jacob B, Selvam D. Qualitative and quantitative analysis of precipitate formation following interaction of chlorhexidine with sodium hypochlorite, neem, and tulsi. J Conserv Dent. 2019; 22: 40-47. PMID: 30820081.

[25]. Rajendran R, Kunjusankaran RN, Sandhya R, Anilkumar A, Santhosh R, Patil SR. Comparative Evaluation of Remineralizing Potential of a Paste Containing Bioactive Glass and a Topical Cream Containing Casein Phosphopeptide-Amorphous Calcium Phosphate: An in Vitro Study. Pesqui Bras Odontopediatria Clin Integr. 2019; 19: 1-10.

[26]. Govindaraju L, Neelakantan P, Gutmann JL. Effect of root canal irrigating solutions on the compressive strength of tricalcium silicate cements. Clin Oral Investig. 2017; 21: 567-71. PMID: 27469101.

[27]. Surathu N, Ramesh S. Root canal morphology of maxillary first molars using cone beam computed tomography. IOSR J Dent Med Sci. 2015; 14:1-4.

[28]. Schultrich B. Strength of cemented carbides. Mechanical Properties of Brittle Materials, in: Modern. 1985.

[29]. Jagadish S, Yogesh BG. Fracture resistance of teeth with Class 2 silver amalgam, posterior composite, and glass cermet restorations. Oper Dent. 1990; 15: 42-7. PMID: 2374743.

[30]. Cötert HS, Sen BH, Balkan M. In vitro comparison of cuspal fracture resistances of posterior teeth restored with various adhesive restorations. Int J Prosthodont. 2001; 14: 374-8. PMID: 11508095.

[31]. Hood JA. Biomechanics of the intact, prepared and restored tooth: some clinical implications. Int Dent J. 1991; 41: 25-32. PMID: 2004835.

[32]. Santos MJMC, Bezerra RB. Fracture resistance of maxillary premolars restored with direct and indirect adhesive techniques. J Can Dent Assoc. 2005; 71: 585. PMID: 16202199.

[33]. Gu YW, Yap AUJ, Cheang P, Khor KA. Effects of incorporation of HA $\mathrm{ZrO} 2$ into glass ionomer cement (GIC). Biomaterials. 2005; 26: 713-20. PMID: 15350775

[34]. Gu YW, Yap AUJ, Cheang P, Koh YL, Khor KA. Development of zirconiaglass ionomer cement composites. J Non-Cryst Solids. 2005; 351: 508-14.

[35]. Mason PN, Ferrari M. In vivo evaluation of glass-ionomer cement adhesion to dentin. Quintessence Int. 1994; 25: 499-504. PMID: 7991772.

[36]. Cunningham MP, Meiers JC. The effect of dentin disinfectants on shear bond strength of resin-modified glass-ionomer materials. Quintessence Int. 1997; 28: 545-51. PMID: 9477883.

[37]. Croll TP, Phillips RW. Six years' experience with glass-ionomer--silver cermet cement. Quintessence Int. 1991; 22.

[38]. Hussainy SN, Nasim I, Thomas T, Ranjan M. Clinical performance of resinmodified glass ionomer cement, flowable composite, and polyacid-modified 
resin composite in noncarious cervical lesions: One-year follow-up. J Conserv Dent. 2018; 21: 510-515. PMID: 30294112.

[39]. Mohanty S, Ramesh S. Fracture resistance of three posterior restorative materials: A preliminary in vitro study. Journal of Advanced Pharmacy Education \& Research. 2017; 7(3).

[40]. Burke FJ, Shaglouf AG, Combe EC, Wilson NH. Fracture resistance of five pin-retained core build-up materials on teeth with and without extracoronal preparation. Oper Dent. 2000; 25: 388-94. PMID: 11203847.

[41]. Poorni S, Srinivasan MR, Nivedhitha MS. Probiotic Streptococcus strains in caries prevention: A systematic review. Journal of conservative dentistry: JCD. 2019 Mar; 22(2): 123.
[42]. Ramarao S, Sathyanarayanan U. CRA Grid - A preliminary development and calibration of a paper-based objectivization of caries risk assessment in undergraduate dental education. J Conserv Dent. 2019; 22: 185-90. PMID: 31142991.

[43]. Khandelwal A, Palanivelu A. Correlation Between Dental Caries And Salivary Albumin In Adult Population In Chennai: An In Vivo Study. BDS. 2019; 22: 228-33.

[44]. Gu YW, Yap AUJ, Cheang P, Khor KA. Zirconia-glass ionomer cement-a potential substitute for Miracle Mix. Scr Mater. 2005; 52: 113-6. 